\title{
Transient Primary Hypothyroidism
}

National Cancer Institute

\section{Source}

National Cancer Institute. Transient Primary Hypothyroidism. NCI Thesaurus. Code C131034.

Primary hypothyroidism that resolves spontaneously. 